\title{
Bilevel Positive Airway Pressure Versus Nasal Continuous Positive Airway Pressure for Prevention of Extubation Failure in Infants After Cardiac Surgery: A Randomized Controlled Trial
}

\section{yirong zheng}

Fujian Medical University

wenpeng xie

Fujian Medical University

jianfeng liu

Fujian Medical University

ning $x u$

Fujian Medical University

hua cao

Fujian Medical University

qiang chen ( $\nabla$ chenqiang2020@163.com )

Fujian Medical University https://orcid.org/0000-0003-3768-9000

\section{Research Article}

Keywords: BiPAP, NCPAP, congenital heart surgery, cardiopulmonary bypass, postoperative care.

Posted Date: March 11th, 2021

DOI: https://doi.org/10.21203/rs.3.rs-271316/v1

License: (c) (i) This work is licensed under a Creative Commons Attribution 4.0 International License.

Read Full License 


\section{Abstract}

Objective: To evaluate the effect of bilevel positive airway pressure (BiPAP) and nasal continuous positive airway pressure (NCPAP) in respiratory support after extubation in infants undergoing cardiac surgery.

Methods: A total of 83 infants who underwent repair of atrial septal defect (ASD) or ventricular septal defect (VSD) after extubation were randomized to the BiPAP group $(n=42)$ or the NCPAP group $(n=41)$ between January 2020 and December 2020. The primary outcomes were the extubation failure rate and the level of $\mathrm{PCO}_{2}$ within $24 \mathrm{~h}$ after extubation.

Results: The baseline characteristics between the two groups were similar. The introduction of BiPAP for post-extubation respiratory support did not reduce extubation failure rates compared to NCPAP $(P>0.05)$. The $\mathrm{PaCO}_{2}$ level within $48 \mathrm{~h}$ was significantly lower in the BiPAP group $(\mathrm{P}<0.05)$. Additionally, the $\mathrm{PaO}_{2} / \mathrm{FiO}_{2}$ in the BiPAP group was significantly higher than that in the NCPAP group at $6 \mathrm{~h}, 12 \mathrm{~h}$ and $24 \mathrm{~h}$ after treatment $(\mathrm{P}<0.05)$. There were no statistically significant differences in duaration on NIV, hospital length of stay, total hospital costs in $\$$ and complications between the two groups $(P>0.05)$.

Conclusion: The introduction of BiPAP for post-extubation respiratory support did not reduce extubation failure rates versus NCPAP. However, BiPAP was shown to be superior to NCPAP in improving oxygenation and carbon dioxide clearance.

\section{What Is Known}

- Extubation failure after congenital heart surgery is associated with prolonged hospital stay and mortality.

- Noninvasive ventilation has been proven to be useful for respiratory support in pediatric patients and can effectively reduce the extubation failure rate in high-risk infants.

\section{What is new}

- The introduction of BiPAP for post-extubation respiratory support did not reduce extubation failure rates versus NCPAP. However, BiPAP was shown to be superior to NCPAP in improving oxygenation and carbon dioxide clearance.

\section{Introduction}

Infants with congenital heart disease (CHD) need respiratory support after surgery because of their young age and poor independent mobility. Noninvasive ventilation (NIV) has been proven to be useful for respiratory support in pediatric patients and can effectively reduce the extubation failure rate in high-risk infants [1-5]. In recent years, the technique of NIV has become increasingly mature, especially the application of bilevel positive airway pressure (BiPAP) and nasal continuous positive airway pressure (NCPAP), which have significantly reduced the application of invasive ventilation and shortened the time 
of mechanical ventilation. NIV has previously been widely used in the field of premature babies and newborns. Studies have confirmed that BiPAP and NCPAP can be used to treat neonatal respiratory failure, respiratory distress syndrome (RDS) and reduce the incidence of bronchopulmonary dysplasia [2,5-8]. However, few studies have focused on the application of NIV in infants with CHD after extubation. We designed this study to evaluate the efficacy and safety of BiPAP and NCPAP as respiratory support modalities after extubation in infants who underwent cardiac surgery.

\section{Methods}

\section{Patients and study design}

We conducted a randomized, controlled study at the cardiac intensive care unit (CICU) of Fujian Maternity and Child Health Hospital, Affiliated Hospital of Fujian Medical University, Fuzhou, China, from January 2020 to December 2020. A total of 83 infants who underwent repair of atrial septal defect (ASD) or ventricular septal defect (VSD) after extubation were randomized to the BiPAP group $(n=42)$ or the NCPAP group $(n=41)$. The families of the patients signed informed consent forms prepared by the Ethics Committee. The trial was approved by the ethics committee of Fujian Maternity and Child Health Hospital (No. 2020KY039) and adhered to the tenets of the Declaration of Helsinki (as revised in 2013).

Inclusion criteria were infants less than 6 months of age with satisfactory anatomical extubation and stable hemodynamics after repair of ASD or VSD. Additional inclusion criteria were infants extubated to NIV support for at least 24 hours to either BiPAP or NCPAP. If patients achieved the following criteria, we would consider extubation: (1) Hemodynamic stability without a large dose of vasoactive drug support; (2) Fraction of inspired oxygen $\left(\mathrm{FiO}_{2}\right) \leq 40 \%$, peak inspiratory pressure (PIP) $\leq 18 \mathrm{cmH}_{2} \mathrm{O}$, and positive end-expiratory pressure (PEEP) 2 4 $\mathrm{cmH}_{2} \mathrm{O}$; and (3) Arterial blood gas (ABG) showing partial pressure of carbon dioxide $\left(\mathrm{PaCO}_{2}\right)<50 \mathrm{mmHg}$, partial pressure of oxygen $\left(\mathrm{PaO}_{2}\right)>70 \mathrm{mmHg}, \mathrm{pH}>7.30$, and lactic acid $<2.0 \mathrm{mmol} / \mathrm{L}$. The exclusion criteria were for patients who had congenital thoracic and abdominal malformations, postoperative extracorporeal membrane oxygenation support or preoperative tracheotomy and intubation, parents who decided not to participate, CICU transfer prior to extubation, or death prior to extubation.

\section{Data Collection and Definitions}

The primary outcomes were the extubation failure rate and the level of $\mathrm{PCO}_{2}$ within $24 \mathrm{~h}$ after extubation. For secondary outcomes, the differences in postoperative duaration on NIV, hospital length of stay, total hospital costs in $\$$ and incidence of complications were analyzed. Besides, we analyzed the changes in ABGs ( $\mathrm{pH}, \mathrm{PaO}_{2}, \mathrm{PaCO}_{2}$, and $\mathrm{PaO}_{2} / \mathrm{FiO}_{2}$ ratio) before and after the treatment in the two groups.

Pulmonary hypertension was defined as a mean pulmonary artery pressure of $25 \mathrm{mmHg}$ or higher [9]. The diagnosis of ventilator-associated pneumonia (VAP) was based on the criteria established by the Centers for Disease Control and Prevention, with diagnosis aided by chest radiographs, positive sputum cultures, 
transtracheal fluid, bronchial washings, and clinical findings [10]. Extubation failure was defined as reintubation within $48 \mathrm{~h}$ after the first planned extubation. Endotracheal intubation was performed when patients developed hypoxemia $\left(\mathrm{FiO}_{2}>0.60\right.$ for target $\left.\mathrm{SpO}_{2}\right)$, respiratory acidosis $\left(\mathrm{pH}<7.20, \mathrm{PaCO}_{2}>65\right.$ $\mathrm{mmHg}$ ), polypnea, or elevated serum lactic acid (>2.0 mmol/L). ABGs were taken before treatment and at $6 \mathrm{~h}, 12 \mathrm{~h}$ and $24 \mathrm{~h}$ after treatment and analyzed using an ABL90 FLEX system.

\section{Ventilation Strategies}

After extubation, BiPAP or NCPAP was connected to infants through silicone binasal prongs. BiPAP or NCPAP was delivered through a time-cycled, pressure-limited, and continuous-flow ventilator (Infant Flow SiPAP system, CareFusion, California, USA), which detected the inspiratory effort of the infants by means of the Graseby abdominal capsule-triggering device. The initial lower and higher respiratory parameters in the BiPAP group were set at $3 \sim 6 \mathrm{cmH}_{2} \mathrm{O}$ and $8 \sim 10 \mathrm{cmH}_{2} \mathrm{O}$, respectively; the $\mathrm{FiO}_{2}$ was $0.21 \sim 0.60$; and the pressure exchange rate was 20 30 exchanges/min. Respiratory settings were adjusted to maintain blood gas analysis within normal ranges. The respiratory parameter settings in the NCPAP group were set at a pressure of $3 \sim 6 \mathrm{cmH}_{2} \mathrm{O}$; the oxygen flow was $6 \sim 8 \mathrm{~L} / \mathrm{min}$; and the $\mathrm{FiO}_{2}$ was $0.21 \sim 0.60$. Respiratory settings were adjusted to maintain blood gas analysis within normal ranges. $\mathrm{SpO}_{2}$ was maintained at 90 95\% during ventilation. After extubation, all infants were administered aerosolized budesonide suspension and terbutaline sulfate solution and intravenously injected with methylprednisolone sodium succinate for anti-inflammation. Patients with excessive phlegm were given intravenous infusion of ambroxol hydrochloride to reduce phlegm and lung physical therapy.

\section{Allocation and blinding}

Randomization was performed using random numbers generated by a computer. Sequentially numbered and sealed opaque envelopes were used to contain group assignments. When the infants were admitted to the $\mathrm{CICU}$ and had satisfied the inclusion criteria, envelopes were opened by the CICU physician, who was not directly involved in the study or the analysis of results. The allocated BiPAP or NCPAP treatment was started immediately. The BiPAP device produces audible noise that cannot be masked. Accordingly, clinicians involved in patient care and researchers assessing study endpoints were not blinded to the nature of the study treatments.

\section{Statistical Analysis}

Sample size estimation was calculated with PASS software (version 15; NCSS LLC, Kaysville, UT, USA). Based on the extubation failure rate in the pre-experiment, assuming the difference between the two independent populations was $10 \%, \alpha=0.05$, and $\beta=0.2$, the number of participants needed was 26 in each group. Assuming a 10\% attrition rate, the total sample size was 58 (29 per group).

The data of this study were analyzed by SPSS 25.0. To demonstrate normal data distribution, a Kolmogorov-Smirnov test was performed before each analysis. If normally distributed, a t-test analysis was performed; otherwise, the Wilcoxon-Mann-Whitney test was applied. For further characterization, we 
performed repeated-measure analysis of variance (two-way ANOVA) and displayed the interaction between and within the study groups. A chi-square test was used to compare the qualitative data between the two groups. A P value $<0.05$ was defined as statistically significant.

\section{Results}

A total of 97 infants were screened between January 2020 and December 2020, of which 7 did not meet the inclusion criteria, 4 underwent preoperative tracheotomy and intubation, and the parents of 2 declined to participate. Finally, 83 infants were ultimately enrolled and finished the trial ( 42 in the BiPAP group; 41 in the NCPAP group) (Fig. 1).

There was no significant difference in extubation failure rates within 48 hours between groups $(7.1 \%$ in the BiPAP group and $9.8 \%$ in the NCPAP group, $P=0.713$, Table 2). Before treatment, there was no significant difference in $\mathrm{pH}, \mathrm{PaO}_{2}, \mathrm{PaCO}_{2}$, or $\mathrm{PaO}_{2} / \mathrm{FiO}_{2}$ between the two groups $(\mathrm{P}>0.05)$. Compared with the values before treatment, the $\mathrm{PaCO}_{2}$ gradually decreased, and the $\mathrm{PH}, \mathrm{PaO}_{2}$, and $\mathrm{PaO}_{2} / \mathrm{FiO}_{2}$ gradually increased after treatment. The $\mathrm{PaCO}_{2}$ of the BiPAP group was significantly lower than that of the NCPAP group at $12 \mathrm{~h}$ and $24 \mathrm{~h}$ after treatment. Additionally, the $\mathrm{PaO}_{2} / \mathrm{FiO}_{2}$ in the BiPAP group was significantly higher than that in the NCPAP group at $6 \mathrm{~h}, 12 \mathrm{~h}$ and $24 \mathrm{~h}$ after treatment. The $\mathrm{pH}, \mathrm{PaO}_{2}, \mathrm{PaCO}_{2}$, and $\mathrm{PaO}_{2} / \mathrm{FiO}_{2}$ were similar between the groups during the entire experiment at other time points (Fig 2). There was no significant difference in duaration on NIV, hospital length of stay, total hospital costs in \$ between the two groups. Furthermore, there was no statistically significant difference in terms of complications. (Table 2).

\section{Discussion}

Persistent hypoxemia often occurs after extubation in patients undergoing cardiac surgery, which affects the prognosis of patients and increases the cost of hospitalization. The reason may be blood contact with foreign matter and organ hypoperfusion during the process of CPB, which leads to an increase in systemic inflammatory mediators and results in lung injury [11-13]. During pulmonary ischemiareperfusion, inflammatory cells infiltrate, pulmonary interstitial exudation increases, and microvilli on the surface of type II alveolar epithelial cells decrease in abundance. Therefore, patients are more likely to have complications such as alveolar collapse, atelectasis, acute respiratory failure, pulmonary infection, and so on $[14,15]$. At the same time, during invasive mechanical ventilation, alveolar mechanical ectasia and partial alveolar structure destruction cause lung injury and airway remodeling [16-18]. Therefore, for these kinds of patients, the NIV transition is usually required after extubation.

NIV mainly includes NCPAP, BiPAP, high-flow nasal cannula, nasal intermittent positive pressure ventilation, and so on. Compared with invasive ventilation, NIV can significantly reduce VAP and other serious mechanical ventilation-related complications, relieve patients' pain and make it easy for patients to accept ventilation $[19,20]$. Moreover, NIV can reduce respiratory work and provide positive airway pressure by heating and humidifying airflow into the nasopharynx so that infants can obtain different 
levels and frequencies of respiratory support. In the past three decades, there has been an increasing number of studies on NIV in pediatrics. The main indications are obstructive sleep apnea syndrome, restrictive lung diseases, apnea of prematurity, acute and chronic respiratory failure, etc. [1,4,21,22]. However, there are few studies on the application of NIV in infants who underwent cardiac surgery.

Extubation failure after congenital heart surgery is associated with prolonged hospital stay and mortality [23]. Studies have shown that BiPAP could reduce the need for reintubation, especially in patients with respiratory failure and cardiogenic pulmonary edema [24-25]. In this study, we found that a total of 7 patients were reintubated within $48 \mathrm{~h}$, with an incidence of only $8.4 \%$. However, there was no significant difference in the extubation failure rate between the two groups. This may be due to the different research subjects and interventions applied. Multicenter studies with larger sample sizes may be needed in the future to further confirm this conclusion.

Our study showed that in the two groups, the $\mathrm{PaO}_{2}$ and $\mathrm{PaO}_{2} / \mathrm{FiO}_{2}$ gradually increased, the $\mathrm{PaCO}_{2}$ gradually decreased after treatment. Continuous airflow impact of NCPAP can reduce upper airway resistance, limit thoracic deformation, supply natural work of breathing, maintain alveolar functional residual capacity, prevent alveolar collapse, and reduce the consumption of autologous alveolar surfactant so that NCPAP can improve alveolar ventilation and reduce the use of exogenous pulmonary surfactant and invasive ventilation [26,27]. At present, NCPAP is still widely used as the initial mode of respiratory support in the clinic. BiPAP not only retains the characteristics of NCPAP but also combines the advantages of the pressure support/pressure control ventilation mode. BiPAP provides two different levels of pressure support during the respiratory cycle, and patients can breathe spontaneously completely under high pressure and low pressure, avoiding the problem of man-machine confrontation $[28,29]$. After a certain period of treatment, $\mathrm{PaO}_{2} / \mathrm{FiO}_{2}$ in the BiPAP group was higher than that in the NCPAP group, while $\mathrm{PaCO}_{2}$ in the BiPAP group was lower than that in the NCPAP group. The reason may be that compared with NCPAP, BiPAP can intermittently give higher pressure support based on PEEP, which is conducive to improving oxygenation and removing carbon dioxide. Therefore, BiPAP has a better respiratory support effect, better oxygenation improvement function and $\mathrm{CO}_{2}$ emission effect [30-31].

We found that there were no statistically significant differences between BiPAP and NCPAP in terms of duaration on NIV, hospital length of stay, total hospital costs in \$, and ventilator-related complications. Zoremba et al. noted that short-term use of BiPAP improved lung function within $24 \mathrm{~h}$ in their study [32]. Compared with endotracheal intubation, BiPAP is more comfortable, has lower rates of mortality and iatrogenic infection, and helps to avoid ventilator-related complications such as VAP and the need for deep sedation [33-35]. Other advantages include oxygenation improvement and respiratory work reduction, resulting in lower myocardial oxygen demand. Diaphragmatic paralysis or dysfunction is common in patients who underwent cardiac surgery, and it can also be used as an indication for the application of BiPAP [36]. Tobias's study showed a decrease in the respiratory rate and $\mathrm{PaCO}_{2}$ in postoperative patients [37]. These patients were in a state of impending respiratory failure, and BiPAP improved oxygenation, lowered carbon dioxide levels and avoided reintubation. 
Our study has several limitations. First, the obvious limitation is the small sample size. This study was conducted at a single center, which limits the generalizability. Second, the medical staff could not be blinded to the randomized mode of support. Although we used objective failure criteria and management protocols, the possibility of a bias might exist. Third, although the short-term effects of NIV on ventilation were considered, the relationship between NIV and long-term clinical outcomes was not shown.

\section{Conclusions}

In summary, the introduction of BiPAP for post-extubation respiratory support did not reduce extubation failure rates versus NCPAP. However, BiPAP is shown to be superior to NCPAP in improving oxygenation and carbon dioxide clearance. Before the routine clinical application of this ventilation mode, more research is needed in the future to confirm its effectiveness and safety.

\section{Abbreviations}

BiPAP--bilevel positive airway pressure

NCPAP--nasal continuous positive airway pressure

$\mathrm{CHD}--$ congenital heart disease

NIV--noninvasive ventilation

RDS--respiratory distress syndrome

ASD--trial septal defect

VSD--ventricular septal defect

CPB--cardiopulmonary bypass

$\mathrm{CICU}--$ cardiac intensive care unit

ABG--arterial blood gas

VAP --ventilator-associated pneumonia

\section{Declarations}

\section{Acknowledgments}

We highly acknowledge the contribution by the participating researchers: Qi-Liang Zhang, Wang-Sheng Dai, Ze-Wei Lin, Li-Wen Wang, Jing Wang and Ling-Shan Yu.

\section{Author contributions}


Qiang Chen and Yirong Zheng conceived the idea; Wen-Peng, Xie and Jian-Feng Liu conducted the analyses; Ning Xu provided the data; all authors contributed to the writing and revisions.

\section{Availability of data and material: N/A}

Code availability: N/A

Ethical approval and consent to participate: Parental informed consent

was obtained from all patients.

Consent for publication: This study was approved by the local Ethical Assistance Committee and the institutional review board. This study was approved by the local Ethical Assistance Committee and the institutional review board.

Conflict of interest: The authors declare no competing interests.

Funding: There was no funding for this research.

\section{References}

1. Cao H, Li H, Zhu X, Wang L, Yi M, Li C, Chen L, Shi Y (2020) Three non-invasive ventilation strategies for preterm infants with respiratory distress syndrome: a propensity score analysis. Archives of medical science : AMS 16 (6):1319-1326. doi:10.5114/aoms.2020.93541

2. Atag E, Krivec U, Ersu R (2020) Non-invasive Ventilation for Children With Chronic Lung Disease. Frontiers in pediatrics 8:561639. doi:10.3389/fped.2020.561639

3. Praud JP (2020) Long-Term Non-invasive Ventilation in Children: Current Use, Indications, and Contraindications. Frontiers in pediatrics 8:584334. doi:10.3389/fped.2020.584334

4. Shi Y, Muniraman H, Biniwale M, Ramanathan R (2020) A Review on Non-invasive Respiratory Support for Management of Respiratory Distress in Extremely Preterm Infants. Frontiers in pediatrics 8:270. doi:10.3389/fped.2020.00270

5. Ramaswamy VV, Bandyopadhyay T, Nanda D, Bandiya P, More K, Oommen VI, Gupta A (2020) Efficacy of noninvasive respiratory support modes as postextubation respiratory support in preterm neonates: A systematic review and network meta-analysis. Pediatric pulmonology 55 (11):29242939. doi:10.1002/ppul.25007

6. Ramaswamy VV, More K, Roehr CC, Bandiya P, Nangia S (2020) Efficacy of noninvasive respiratory support modes for primary respiratory support in preterm neonates with respiratory distress syndrome: Systematic review and network meta-analysis. Pediatric pulmonology 55 (11):2940-2963. doi:10.1002/ppul.25011

7. Ho JJ, Subramaniam P, Davis PG (2020) Continuous positive airway pressure (CPAP) for respiratory distress in preterm infants. The Cochrane database of systematic reviews 10:Cd002271. 
doi:10.1002/14651858.CD002271.pub3

8. Glaser K, Speer CP, Wright CJ (2019) Fine Tuning Non-invasive Respiratory Support to Prevent Lung Injury in the Extremely Premature Infant. Frontiers in pediatrics 7:544. doi:10.3389/fped.2019.00544

9. Badesch DB, Champion HC, Sanchez MA, Hoeper MM, Loyd JE, Manes A, McGoon M, Naeije R, Olschewski H, Oudiz RJ, Torbicki A (2009) Diagnosis and assessment of pulmonary arterial hypertension. Journal of the American College of Cardiology 54 (1 Suppl):S55-66. doi:10.1016/j.jacc.2009.04.011

10. Horan TC, Andrus M, Dudeck MA (2008) CDC/NHSN surveillance definition of health care-associated infection and criteria for specific types of infections in the acute care setting. American journal of infection control 36 (5):309-332. doi:10.1016/j.ajic.2008.03.002

11. Durham AL, Al Jaaly E, Graham R, Brook PO, Bae JH, Heesom KJ, Postle AD, Lavender P, Jazrawi E, Reeves B, Fiorentino F, Mumby S, Angelini GD, Adcock IM (2020) Multi-omic analysis of the effects of low frequency ventilation during cardiopulmonary bypass surgery. International journal of cardiology 309:40-47. doi:10.1016/j.ijcard.2020.03.054

12. Schlensak C, Doenst T, Preusser S, Wunderlich M, Kleinschmidt M, Beyersdorf F (2002)

Cardiopulmonary bypass reduction of bronchial blood flow: a potential mechanism for lung injury in a neonatal pig model. The Journal of thoracic and cardiovascular surgery 123 (6):1199-1205. doi:10.1067/mtc.2002.121977

13. Deng Y, Hou L, Xu Q, Liu Q, Pan S, Gao Y, Dixon RAF, He Z, Wang X (2020) Cardiopulmonary Bypass Induces Acute Lung Injury via the High-Mobility Group Box 1/Toll-Like Receptor 4 Pathway. Disease markers 2020:8854700. doi:10.1155/2020/8854700

14. Karacalilar M, Onan IS, Onan B, Sen O, Gonca S, Solakoglu S, Yeniterzi M (2020) Effects of pulmonary perfusion during cardiopulmonary bypass on lung functions after cardiac operation. Journal of cardiac surgery 35 (10):2469-2476. doi:10.1111/jocs.14934

15. Lin X, Ma X, Cui X, Zhang R, Pan H, Gao W (2020) Effects of Erythropoietin on Lung Injury Induced by Cardiopulmonary Bypass After Cardiac Surgery. Medical science monitor : international medical journal of experimental and clinical research 26:e920039. doi:10.12659/msm.920039

16. Wang Q, Xu GX, Tai QH, Wang Y (2020) Lipoxin A4 Reduces Ventilator-Induced Lung Injury in Rats with Large-Volume Mechanical Ventilation. Mediators of inflammation 2020:6705985. doi:10.1155/2020/6705985

17. Slutsky AS, Ranieri VM (2013) Ventilator-induced lung injury. The New England journal of medicine 369 (22):2126-2136. doi:10.1056/NEJMra1208707

18. Kneyber MC, Zhang H, Slutsky AS (2014) Ventilator-induced lung injury. Similarity and differences between children and adults. American journal of respiratory and critical care medicine 190 (3):258265. doi:10.1164/rccm.201401-0168CP

19. Ferrer M, Sellares J, Torres A (2014) Noninvasive ventilation in withdrawal from mechanical ventilation. Seminars in respiratory and critical care medicine 35 (4):507-518. doi:10.1055/s-00341383865 
20. Wang T, Zhang L, Luo K, He J, Ma Y, Li Z, Zhao N, Xu Q, Li Y, Yu X (2016) Noninvasive versus invasive mechanical ventilation for immunocompromised patients with acute respiratory failure: a systematic review and meta-analysis. BMC pulmonary medicine 16 (1):129. doi:10.1186/s12890-016-0289-y

21. Amaddeo A, Frapin A, Fauroux B (2016) Long-term non-invasive ventilation in children. The Lancet Respiratory medicine 4 (12):999-1008. doi:10.1016/s2213-2600(16)30151-5

22. Essouri S, Carroll C (2015) Noninvasive support and ventilation for pediatric acute respiratory distress syndrome: proceedings from the Pediatric Acute Lung Injury Consensus Conference. Pediatric critical care medicine : a journal of the Society of Critical Care Medicine and the World Federation of Pediatric Intensive and Critical Care Societies 16 (5 Suppl 1):S102-110. doi: $10.1097 /$ pcc. 0000000000000437

23. Richter RP, Alten JA, King RW, et al (2019) Positive Airway Pressure Versus High-Flow Nasal Cannula for Prevention of Extubation Failure in Infants After Congenital Heart Surgery. Pediatr Crit Care Med 20(2):149-157. doi:10.1097/PCC.0000000000001783

24. David-João PG, Guedes MH, Réa-Neto Á, Chaiben VBO, Baena CP (2019) Noninvasive ventilation in acute hypoxemic respiratory failure: A systematic review and meta-analysis. Journal of critical care 49:84-91. doi:10.1016/j.jcrc.2018.10.012

25. Park M, Sangean MC, Volpe Mde S, Feltrim MI, Nozawa E, Leite PF, Passos Amato MB, Lorenzi-Filho G (2004) Randomized, prospective trial of oxygen, continuous positive airway pressure, and bilevel positive airway pressure by face mask in acute cardiogenic pulmonary edema. Critical care medicine 32 (12):2407-2415. doi:10.1097/01.ccm.0000147770.20400.10

26. Gizzi C, Montecchia F, Panetta V, Castellano C, Mariani C, Campelli M, Papoff P, Moretti C, Agostino R (2015) Is synchronised NIPPV more effective than NIPPV and NCPAP in treating apnoea of prematurity (AOP)? A randomised cross-over trial. Archives of disease in childhood Fetal and neonatal edition 100 (1):F17-23. doi:10.1136/archdischild-2013-305892

27. Alexiou S, Panitch HB (2016) Physiology of non-invasive respiratory support. Seminars in fetal \& neonatal medicine 21 (3):174-180. doi:10.1016/j.siny.2016.02.007

28. Xia J, Zhang H, Sun B, Yang R, He H, Zhan Q (2014) Spontaneous breathing with biphasic positive airway pressure attenuates lung injury in hydrochloric acid-induced acute respiratory distress syndrome. Anesthesiology 120 (6):1441-1449. doi:10.1097/aln.0000000000000259

29. Abramo T, Williams A, Mushtaq S, Meredith M, Sepaule R, Crossman K, Burney Jones C, Godbold S, Hu Z, Nick T (2017) Paediatric ED BiPAP continuous quality improvement programme with patient analysis: 2005-2013. BMJ open 7 (1):e011845. doi:10.1136/bmjopen-2016-011845

30. Vitaliti G, Wenzel A, Bellia F, Pavone P, Falsaperla R (2013) Noninvasive ventilation in pediatric emergency care: a literature review and description of our experience. Expert review of respiratory medicine 7 (5):545-552. doi:10.1586/17476348.2013.816570

31. Moret lurilli C, Brunetti ND, Di Corato PR, Salvemini G, Di Biase M, Ciccone MM, Procacci V (2018) Hyperacute Hemodynamic Effects of BiPAP Noninvasive Ventilation in Patients With Acute Heart 
Failure and Left Ventricular Systolic Dysfunction in Emergency Department. Journal of intensive care medicine 33 (2):128-133. doi:10.1177/0885066617740849

32. Zoremba M, Kalmus G, Begemann D, Eberhart L, Zoremba N, Wulf H, Dette F (2011) Short term noninvasive ventilation post-surgery improves arterial blood-gases in obese subjects compared to supplemental oxygen delivery - a randomized controlled trial. BMC anesthesiology 11:10. doi:10.1186/1471-2253-11-10

33. Hess DR (2005) Noninvasive positive-pressure ventilation and ventilator-associated pneumonia. Respiratory care 50 (7):924-929; discussion 929-931

34. Hamid M, Akhtar Ml, Ahmed S (2020) Immediate changes in hemodynamics and gas exchange after initiation of noninvasive ventilation in cardiac surgical patients. Annals of cardiac anaesthesia 23 (1):59-64. doi:10.4103/aca.ACA_69_18

35. Landoni G, Augoustides JG, Guarracino F et al (2011) Mortality reduction in cardiac anesthesia and intensive care: results of the first International Consensus Conference. Acta anaesthesiologica Scandinavica 55 (3):259-266. doi:10.1111/j.1399-6576.2010.02381.x

36. Kotecha S, Buchan C, Parker K, Toghill J, Paul E, Miller B, Naughton M, Snell G, Dabscheck E (2018) Domiciliary non-invasive ventilation post lung transplantation. Respirology (Carlton, Vic) 23 (1):9699. doi:10.1111/resp. 13160

37. Tobias JD (2000) Noninvasive ventilation using bilevel positive airway pressure to treat impending respiratory failure in the postanesthesia care unit. Journal of clinical anesthesia 12 (5):409-412. doi:10.1016/s0952-8180(00)00172-0

\section{Tables}

Table 1 Demographic data of patients included in the two groups

\begin{tabular}{|llll|}
\hline Items & BiPAP $₫ \mathrm{n}=42 \rrbracket$ & NCPAP $₫ \mathrm{n}=41 \rrbracket$ & $P$-value \\
\hline Gender $(\mathrm{M} / \mathrm{F})$ & $28 / 14$ & $25 / 16$ & 0.693 \\
\hline Age (months; mean $\pm \mathrm{SD})$ & $1.8 \pm 1.0$ & $1.7 \pm 0.8$ & 0.551 \\
\hline Weight $(\mathrm{kg} ;$ mean $\pm \mathrm{SD})$ & $4.4 \pm 1.7$ & $4.6 \pm 1.5$ & 0.688 \\
\hline ASD/VSD & $20 / 22$ & $22 / 19$ & 0.582 \\
\hline Operation time (h; mean $\pm \mathrm{SD})$ & $3.8 \pm 1.2$ & $4.0 \pm 1.1$ & 0.382 \\
\hline CPB time (h; mean $\pm \mathrm{SD})$ & $1.4 \pm 0.3$ & $1.5 \pm 0.3$ & 0.694 \\
\hline Respiratory failure, $\mathrm{n}(\%)$ & $12(28.6)$ & $11(26.8)$ & 0.181 \\
\hline Pneumonia, $\mathrm{n}(\%)$ & $27(64.2)$ & $25(61.0)$ & 0.755 \\
\hline Pulmonary hypertension, $\mathrm{n}(\%)$ & $31(73.8)$ & $29(70.7)$ & 0.754 \\
\hline
\end{tabular}


Abbreviations: ASD, atrial septal defect; VSD, ventricular septal defect; CPB, cardiopulmonary bypass.

Table 2 Outcomes and complications of the two groups.

\begin{tabular}{|c|c|c|c|}
\hline \multirow[t]{2}{*}{ Items } & BiPAP & NCPAP & \multirow[t]{2}{*}{$P$-value } \\
\hline & $\bigotimes n=42 \bigotimes$ & $\bigotimes n=41 \rrbracket$ & \\
\hline Extubation failure, $\mathrm{n}(\%)$ & $3(7.1)$ & $4(9.8)$ & 0.713 \\
\hline Duaration on NIV (h; mean \pm SD) & $49.5 \pm 8.5$ & $48.5 \pm 7.7$ & 0.536 \\
\hline Hospital length of stay (days; mean \pm SD) & $14.5 \pm 5.3$ & $16.2 \pm 4.1$ & 0.153 \\
\hline Total hospital costs in $\$$ (median \pm SD) & $9783 \pm 3520$ & $10210 \pm 4580$ & 0.382 \\
\hline Complications, n (\%) & $10(23.8)$ & $13(31.7)$ & \multirow[t]{7}{*}{0.799} \\
\hline Pneumothorax (n) & 2 & 1 & \\
\hline Feeding intolerance $(\mathrm{n})$ & 3 & 5 & \\
\hline Ventilator-associated pneumonia (n) & 1 & 2 & \\
\hline Sepsis (n) & 2 & 1 & \\
\hline Nasal injury (n) & 2 & 3 & \\
\hline In hospital mortality (n) & 0 & 1 & \\
\hline
\end{tabular}

Abbreviations: NIV, Noninvasive ventilation.

\section{Figures}




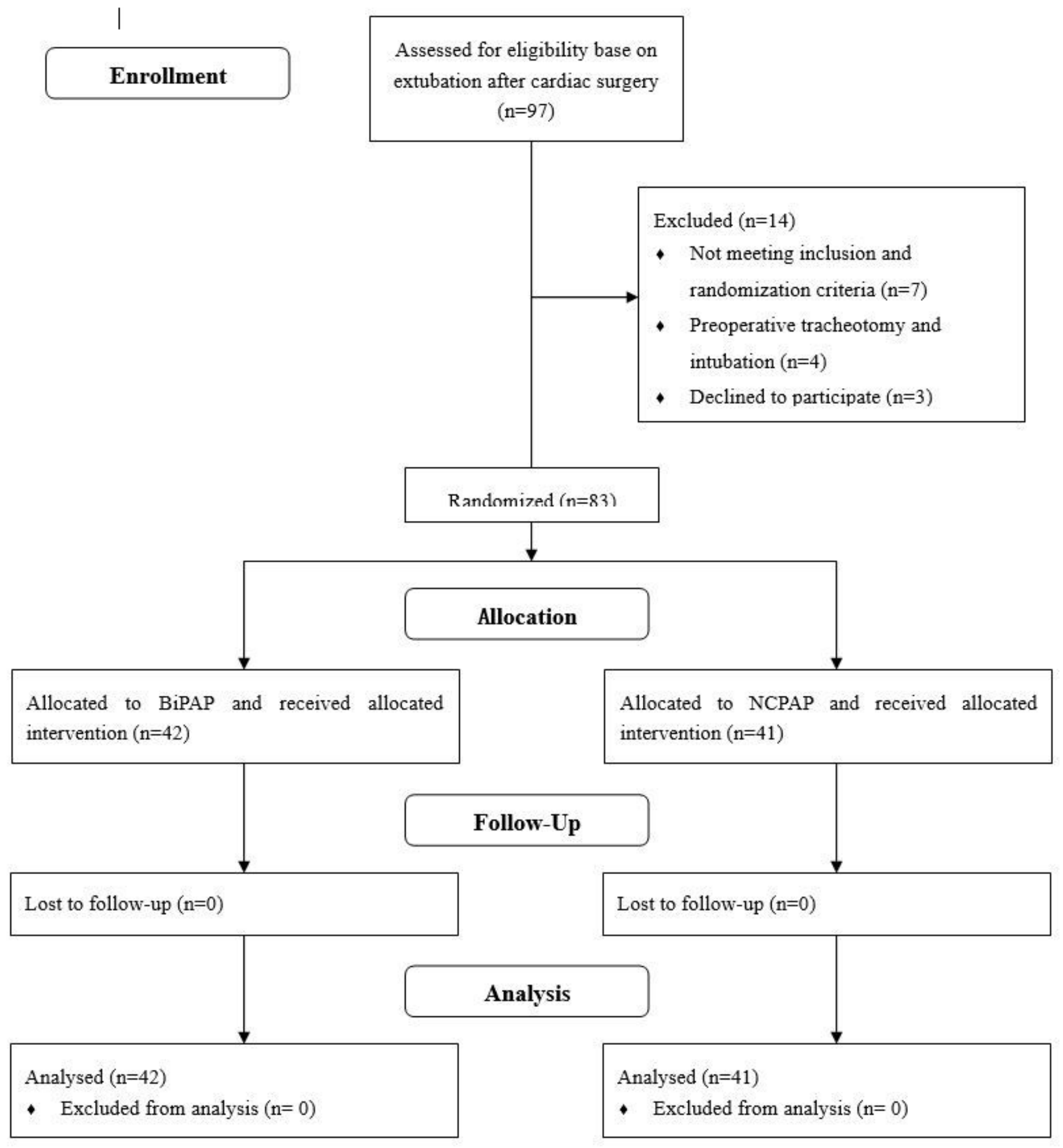

\section{Figure 1}

CONSORT trials flow diagram. CONSORT, Consolidated Standards of Reporting Trials; BiPAP, bilevel positive airway pressure; NCPAP, nasal continuous positive airway pressure. 

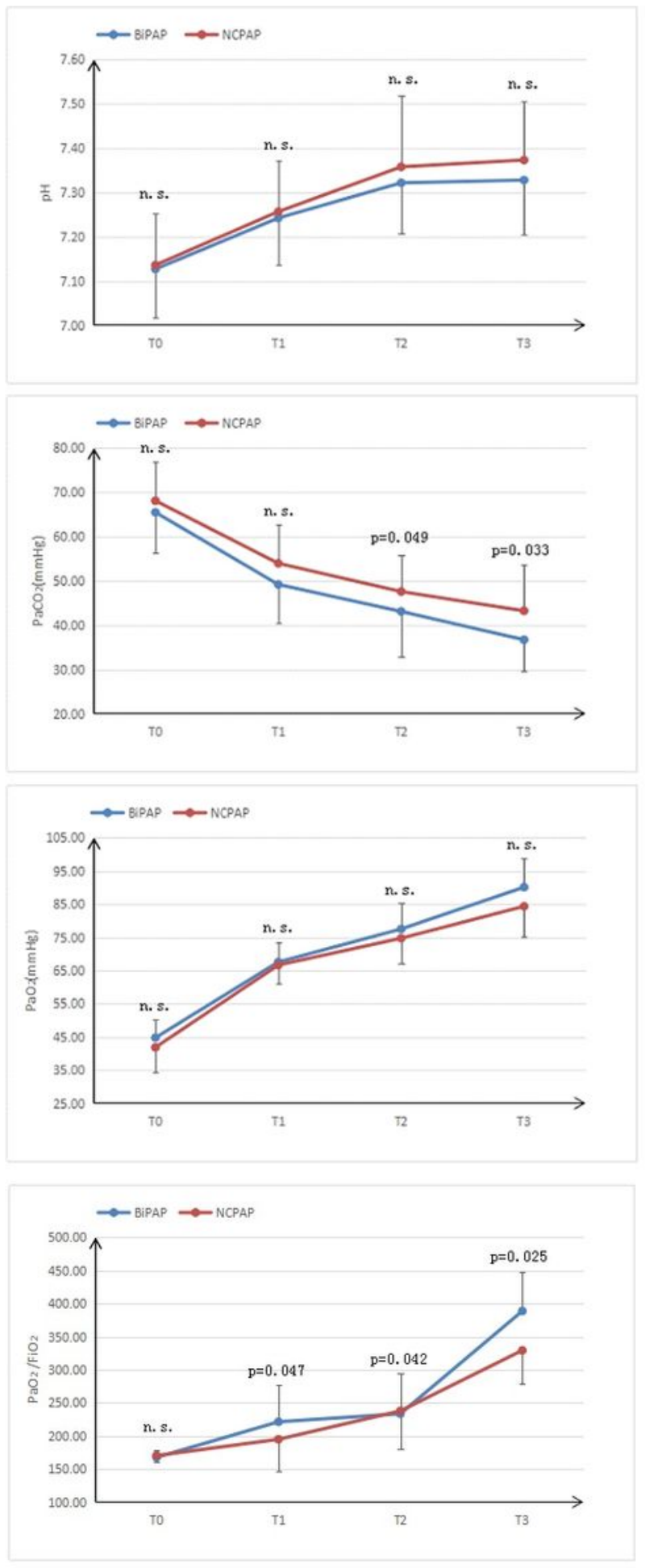

\section{Figure 2}

Blood gas index before treatment and at $6 \mathrm{~h}, 12 \mathrm{~h}$ and $24 \mathrm{~h}$ after treatment. T0=before treatment; T1=at $6 \mathrm{~h}$ after treatment; $\mathrm{T} 2=\mathrm{at} 12 \mathrm{~h}$ after treatment; $\mathrm{T} 3=\mathrm{at} 2 \mathrm{~h}$ after treatment. n.s. $=$ no significance. 